\title{
Mechanical behaviour and microstructural evolution in fine grain Ti-6Al-4V alloy under superplastic conditions
}

\author{
Laurie Despax $^{1, a^{*}}$, Vanessa Vidal ${ }^{1, b}$, Denis Delagnes $^{1, \mathrm{c}}$, Moukrane Dehmas ${ }^{2, \mathrm{~d}}$, Hiroaki Matsumoto ${ }^{3, \mathrm{f}}$ and Vincent Velay ${ }^{1, \mathrm{~g}}$ \\ ${ }^{1}$ Institut Clément Ader (ICA), Université de Toulouse, CNRS, IMT Mines Albi, UPS, INSA, ISAE-SUPAERO, Campus Jarlard, \\ 81013 Albi CT Cedex 09, France. \\ 2 CIRIMAT, Université de Toulouse, CNRS, 4 allée Emile Monso, BP 44362, 31030 Toulouse Cedex 04, France. \\ 3 Department of Advanced Materials Science, Faculty of Engineering, Kagawa University, 2217-20 Hayashi-cho, Takamatsu, \\ Kagawa 761-0396, Japan. \\ *laurie.despax@mines-albi.fr
}

\begin{abstract}
Ti-6Al-4V is able to support high level of deformations like superplastic deformation for aeronautical structural applications. However, the applied temperature during forming induces changes in phase fraction, which may have an impact on the mechanisms of deformation involved and the final part. Mechanisms described in the literature, like dislocation glide, diffusional creep, Grain Boundary Sliding (GBS) accommodated by dislocation or diffusion, are still controversial as there are mainly based on post mortem analysis or on stress-strain data. The purpose of this work was to combine interrupted tensile tests and heat treatments to improve the understanding of the mechanisms of deformation on each stage of deformation. The chosen test temperatures were $750^{\circ} \mathrm{C}$ and $920^{\circ} \mathrm{C}$ which correspond to different $\beta$ phase fractions. The microstructural features like grain size and phase fraction were studied by Scanning Electron Microscope (SEM) combined with image analysis. Moreover, EBSD was used to follow the change of crystalline orientation of $\alpha$ grains to distinguish the involved mechanisms as a function of the deformation. Indeed, it would appears that several mechanisms could be activated depending on the deformation stage and on the temperature.
\end{abstract}

Keywords: Superplasticity, Titanium alloys, Texture, $\beta$-phase fraction, EBSD, pole figure.

\section{Introduction}

Superplastic forming process on titanium alloys (as Ti-6Al-4V) is expensive by requiring high temperatures temperature $\left(\mathrm{T} \geq 900^{\circ} \mathrm{C}\right.$ ) and low strain rates $\left(\dot{\varepsilon} \leq 10^{-3} s^{-1}\right)$. Consequently, many studies deal with the lowering of forming temperature [1] and the reduction of the forming time [2-3] by optimizing the initial microstructure. Indeed, following the initial microstructure (grain size and grain shape - equiaxial, lamellar, martensitic) and the mechanical conditions (temperature, strain rate), the proposed deformation mechanisms are different and have an impact on the final response of the material (softening, hardening). Numerous mechanisms are reported in the literature: dislocation glide, Grain Boundary Sliding (GBS) accommodated by dislocation glide or diffusion [4], diffusional creep for higher temperatures, dislocation climb as well as microstructural changes (dynamic recrystallization, grain growth and grain rotation). The understanding of the deformation mechanisms involved during superplastic forming (SPF) are still a major issue because large part of the studies is based on stress-strain curves or on post-mortem analyses of the $\alpha$ phase. Earlier studies on Ti-6Al-4V showed, by in-situ SEM observations [5], that the predominant mechanism at $800^{\circ} \mathrm{C}$ is the Grain Boundary Sliding (GBS) and dislocation motion in $\alpha$ grains leading to a dynamic recrystallization. At $900^{\circ} \mathrm{C}$, Alabort et al. suggested a mechanism of GBS completed by the motion of dislocations in the $\beta$ phase, which seems to be dependent on the $\beta$ grain size [5]. Otherwise Kim et al. proposed the sliding as a phase boundary sliding rather than GBS due to the presence of dislocations only at $\alpha / \beta$ interfaces [6]. These studies are mainly based on mechanism according the $\alpha$ phase. However at high temperature, the phase fractions and the $\alpha / \beta$ interfaces might be different and so may influence the mechanical behaviour. Furthermore, few studies insist on the understanding of the mechanisms on this high temperatures because they are too far from industrial superplastic favourable conditions [6]. The aim of 
this study will be to improve the understanding of the deformation mechanisms that are involved, in a fine grain Ti-6Al-4V alloy $\left(\mathrm{d}_{\alpha}=2-3 \mu \mathrm{m}\right)$, for a slow strain rate of $10^{-4} \mathrm{~s}^{-1}$ and two extreme temperature conditions $\left(750^{\circ} \mathrm{C}\right.$ and $\left.920^{\circ} \mathrm{C}\right)$, which correspond to very different $\beta$ phase fractions. Therefore, interrupted tensile tests and SEM-EBSD measurements are used to analyse the mechanical behaviour and the microstructural evolution (phase fraction, grain size and $\alpha$ grain orientation) on each step of the deformation.

\section{Material and experiments}

The studied samples are sheets ( $3 \mathrm{~mm}$ thick) of Ti-6Al-4V titanium alloy with a nominal chemical composition of (in wt $\%$ ) $6.25 \mathrm{Al}$, $3.90 \mathrm{~V}, 0.24 \mathrm{Fe}, 0.17 \mathrm{Oand}$ balance titanium. At the as-received state, Ti- $6 \mathrm{Al}-4 \mathrm{~V}$ alloy contained an $\alpha$ phase amount of $88 \%$ in volume and had a $\beta$-transus temperature around $1000^{\circ} \mathrm{C}$. The morphology of the $\alpha$ phase is slightly elongated along the rolling direction. The average size is around $3 \mu \mathrm{m}$. Tensile tests were conducted into a three parts furnace at $750^{\circ} \mathrm{C}$ and $920^{\circ} \mathrm{C}$ with a strain rate of $10^{-4} \mathrm{~s}^{-1}$, under argon atmosphere to limit the oxygen diffusion. The deformation and the temperature were monitored by displacement and thermocouples, respectively. The samples had a form of dog bone cut in the rolling direction (RD). After tensile tests, the cooling was done into the furnace. As a result of this slow cooling, significant growth of the nodular $\alpha$ phase occurred. Interrupted tensile tests were also conducted to study more precisely the microstructure evolution. At $750{ }^{\circ} \mathrm{C}$, the tensile tests were interrupted at $220 \%$ and $700 \%$ of deformation. At $920^{\circ} \mathrm{C}$, the tensile tests were interrupted at $260 \%$ and $740 \%$ corresponding to the maximum displacement allowed by the hydraulic piston of the testing machine. After interrupted tensile tests, the specimens were cooled down in the furnace. SEM observations coupled with image analysis allowed to follow the evolution of the $\alpha$ grain size (measured at RT) as a function of the temperature and the deformation. EBSD was used to follow the change of preferential orientation of grains. The chosen parameters are a magnification of 1000 and a step size of $0.3 \mu \mathrm{m}$ for the temperature of $750^{\circ} \mathrm{C}$ and a magnification of 400 with a step size of $0.4 \mu \mathrm{m}$ for $920^{\circ} \mathrm{C}$. These chosen parameters are a compromise between the huge difference of analysed grain size and the data quality. To determine the evolution of the phase fraction as a function of the temperature without including the contribution of the deformation, heat treatments were carried out under air at different temperatures $\left(700^{\circ} \mathrm{C}\right.$ to $\left.920^{\circ} \mathrm{C}\right)$ with a heating rate about $10^{\circ} \mathrm{C} / \mathrm{min}$. After isothermal holding of $2 \mathrm{~h}$, samples were cooled by water quenching at room temperature to freeze the high temperature microstructure. Indeed only the $\beta$ phase involved at high temperature will decompose into a fine $\alpha$ ' martensitic phase during cooling. The microstructure was observed with a SEM (NOVANANOSEM 450) by using backscattered electron (BSE) mode and the microstructural features ( $\alpha$ phase fraction, $\alpha$ grain size) were determined by image analysis.

\section{Results}

As shown in Fig.1a, the as-received microstructure is characterized by a weak morphological texture consisting of $\alpha$ grains slightly elongated along the RD with a $\beta$ phase distributed around those grains. The $\alpha$ phase appears in dark and the $\beta$ phase in light. The $\alpha$ phase amount was determined on the sample surface along three directions (rolling direction (RD), normal direction (ND), transversal direction (TD)) by BSE-SEM and image analysis. The $\alpha$ phase fractions obtained for each direction (Fig. 1a-1b) were found to be quite similar and about $87 \%$. As a consequence, the rolling side (RD-TD) surface was analyzed and considered as representative of the material. 
a)

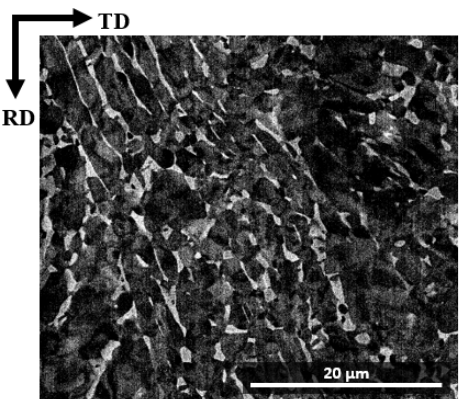

b)

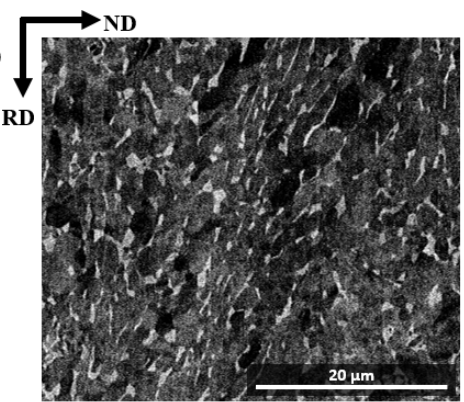

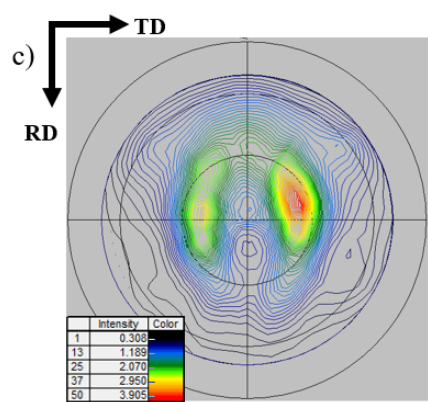

Figure 1: Ti-6Al-4V as-received state observed by BSE-SEM along the rolling side (a) and normal side (b). (0001) pole figure measured by X-Ray Diffraction showing the initial texture of the $\alpha$ phase using an iso-lines presentation with normalized intensity values (c).

The $\{0001\}$ pole figure of the $\alpha$ phase determined by X-Ray Diffraction (XRD) indicates a rolling texture with basal plan $\{0001\}$ tilted by $+/-25^{\circ}$ from the ND to the RD (Fig.1c). The Ti-6Al-4V studied thus has crystallographic and morphologic texture. Fig.2b displays the $\alpha$ phase fraction evolution after different isothermal holding temperatures and water quenching. These experimental data obtained by image analysis from SEM images (e.g.Fig.2a) were compared with those predicted at the thermodynamic equilibrium. The calculation were made with the Thermo-Calc software using Saunders database for titanium systems. With the exception of the as-received state, a good agreement can be found in the studied temperature range. This funding means that the microstructure is close to the equilibrium state after $2 \mathrm{~h}$ of isothermal holding time in the studied temperature range [7]. In the case of the as-received state, the $\alpha$ phase amount obtained experimentally is about $87 \mathrm{vol} \%$ whereas the equilibrium $\alpha$ phase fraction is about 95 vol\%. This difference can be due to the kinetics effects at low temperature or to the extrapolation made by the thermodynamic calculation below $400^{\circ} \mathrm{C}$.

a)

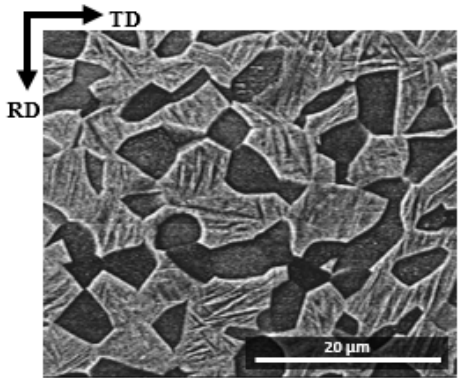

b)

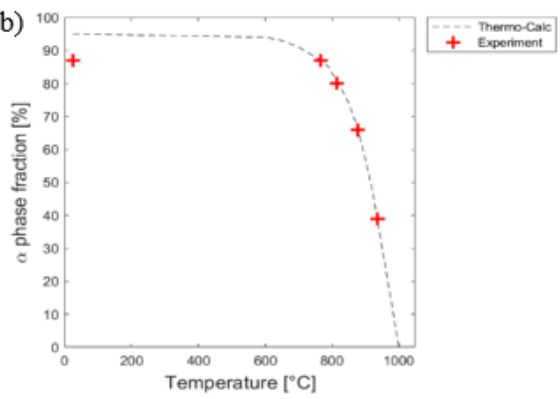

Figure 2: $\alpha$ phase fraction evolution as a function of the temperature. SEM picture obtained after heat treatment at $920^{\circ} \mathrm{C} / 2 \mathrm{~h}$ and water quenching (a). Comparison between experimental results obtained after image analysis and Thermo-Calc@ data (b).

The true strain-stress curves were used to describe the steady-state flow and then determine the mechanical behaviour. The resulting microstructure and the grain orientation were characterized by SEM and EBSD, respectively. Fig. 3a shows true strain-stress curves obtained after tensile tests at $750^{\circ} \mathrm{C}$ and $920^{\circ} \mathrm{C}$ with a low strain rate of $10^{-4} \mathrm{~s}^{-1}$. These temperatures were chosen because the $\beta$ phase fraction is different and may have an impact on the mechanical behaviour: around $11 \mathrm{vol} \%$ at $750^{\circ} \mathrm{C}$ and around $50 \mathrm{vol} \%$ at $920^{\circ} \mathrm{C}$ (Fig.2b). It can be noticed that the strain-stress response is reproducible through the interrupted tensile tests at $750^{\circ} \mathrm{C}$ but at $920^{\circ} \mathrm{C}$, a slight difference on stress could be observed (Fig.3a). At $750^{\circ} \mathrm{C}$, after an initial strain hardening and a slight softening (40\% of elongation), a steady-state flow characteristics of a superplastic flow occurs and is followed by a slight strain hardening ( $220 \%$ of elongation) and then by a strain softening until the final elongation of $700 \%$. At $920^{\circ} \mathrm{C}$, the stress-strain curve reveals a pronounced 
flow hardening with a low stress level on the first deformation stage. As seen on the Fig.3b and c, microstructures obtained after tensile tests and slow cooling rate change in terms of $\alpha$ grain size and can give some information about the mechanisms involved. However, this feature needs to be used with caution because the final $\alpha$ grain size is impacted by the tensile test duration at high temperature (7h), the slow cooling rate and the applied stress. After tensile test at $750^{\circ} \mathrm{C}$, the morphology of $\alpha$ grains seems to be equiaxed (no more elongated along the RD) and their size is still about $3 \mu \mathrm{m}$ (Fig. 1a). At $920^{\circ} \mathrm{C}$, the $\alpha$ grain size was found to be about $10.8 \pm 3.8 \mu \mathrm{m}$. The thermal and mechanical impact on the $\alpha$ grains size is most important at $920^{\circ} \mathrm{C}-10^{-4} \mathrm{~s}^{-1}$ than at $750^{\circ} \mathrm{C}-10^{-4}$ $\mathrm{s}^{-1}$. Moreover, at $920^{\circ} \mathrm{C}$, the number density of $\alpha$ grains is lower than at $750^{\circ} \mathrm{C}$.
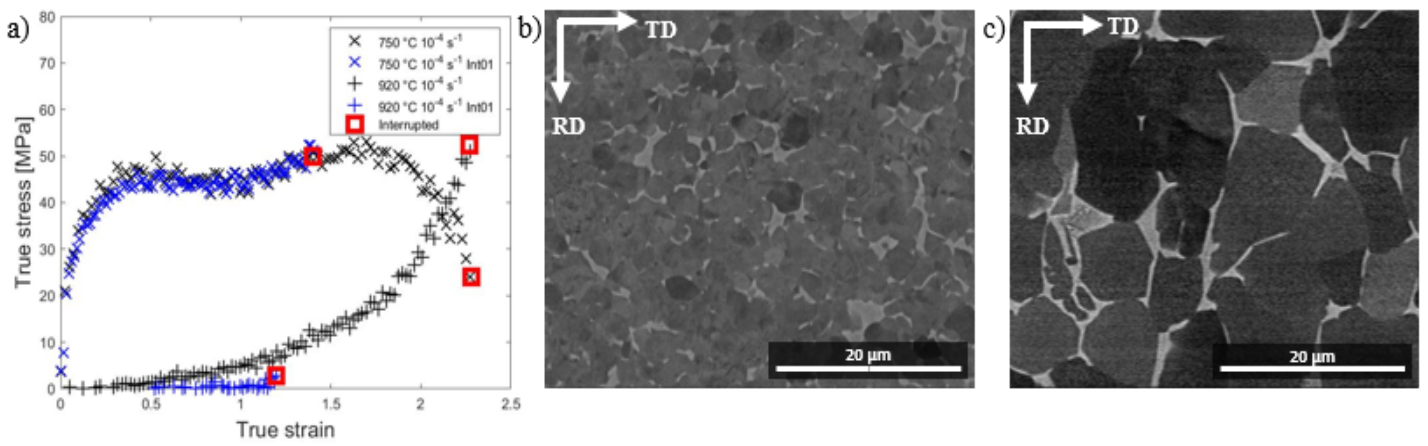

Figure 3: True strain-stress curves obtained after tensile test with a strain rate of $10^{-4} \mathrm{~s}^{-1}$ at $750^{\circ} \mathrm{C}$ and $920^{\circ} \mathrm{C}$ (a). The red cubic open symbols correspond to the location of interrupted points and the blue lines correspond to the interrupted curves at each temperature. SEM images obtained after tensile test at $750^{\circ} \mathrm{C}$ (b) and $920^{\circ} \mathrm{C}$ (c).

The EBSD pole figures were preferred to follow the evolution of the crystalline orientation of $\alpha$ grains at each elongation step for the two temperatures. The $\{0001\}$ plan was considered on tensile test samples obtained at $750^{\circ} \mathrm{C}$ and $920^{\circ} \mathrm{C}$ and are represented in the figure.4b-c and figure.4d-e, respectively. As a reminder, these data were recorded after tensile tests and slow cooling rate. Consequently, the mechanism of grain growth was involved. However, it can be assumed that this grain growth during cooling will not impact the orientation of grains [10] considering no nucleation of $\alpha$ phase. As already shown in the figure.1b, the initial state is characterized by a preferential orientation of the $\{0001\}$ plan (Fig.4a). Following $220 \%$ of elongation at $750^{\circ} \mathrm{C}$, the distribution of the crystalline orientation is more spread with respect to the as-received state, characterizing a slight randomization of crystalline orientation of $\alpha$ grains. At the failure (700\% of elongation), Fig. $4 \mathrm{c}$ reveals that the $\{0001\}$ pole orientation changes in addition to the decrease of intensity. The intensity of the $\{0001\}$ plan is still important but at $90^{\circ}$ to the normal to the sample surface. At $920^{\circ} \mathrm{C}$, a slight loss of the preferential orientation of grains can be noticed with the decrease of the pole figure intensity. In fact, some grains seem to keep a weak texture $\{0001\}$ parallel to the sample surface with some other grains randomly distributed around this main direction (Fig.4d and 4e). 
a)

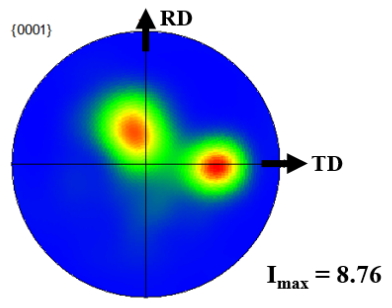

b)

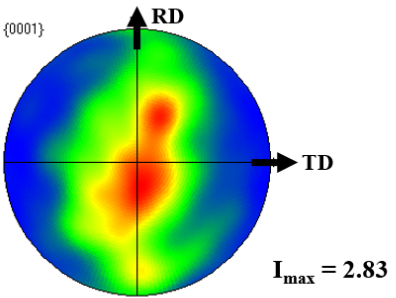

d)

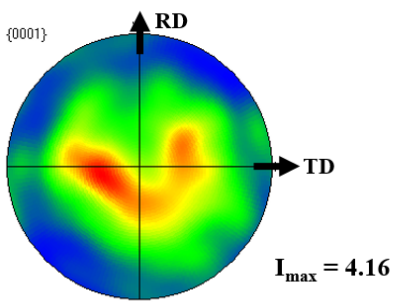

c)

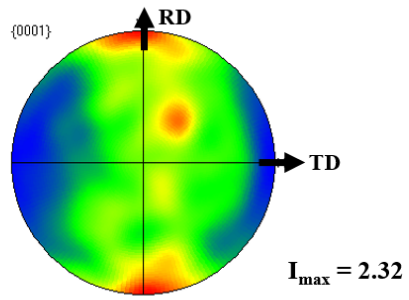

e)

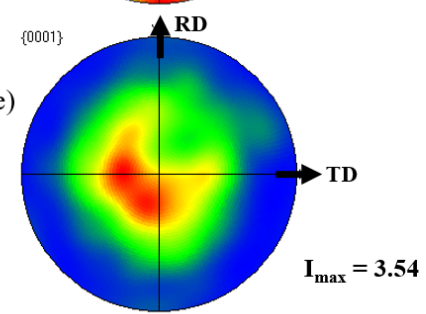

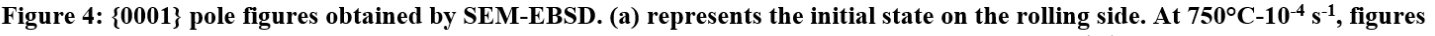
representing the interrupted $220 \%$ and the broken one are $b$ and $c$, respectively. At $920^{\circ} \mathrm{C}-10^{-4} \mathrm{~s}^{-1}$, the d and e pole figures represent the interrupted test at $260 \%$ and $740 \%$, respectively. The RD corresponds to the Y0 axis.

\section{Discussion}

Regarding the $750^{\circ} \mathrm{C}$ condition, the mechanical flow consists of various phenomena (Fig.3a). The slight strain hardening at the earlier stage of deformation could be explained by the dislocation glide activity and then upon additional deformation. Their rearrangement could lead to a dynamic globularization of the $\alpha$ grains [8] as observed with the final microstructure (Fig. 3b), which is nodular instead of having a slightly elongated shape (Fig.1a). The steady-state flow characteristics of superplastic flow could be representative of the GBS activation. Indeed, the small $\alpha$ nodules previously formed and the temperature ( $\beta$ phase is sufficient to be homogeneously distributed around the $\alpha$ grains) could favoured the activation of GBS [11]. As seen on the Fig.4, a decrease of the pole figure intensity was observed, that could confirm this hypothesis, but the texture is not totally lost as expected with GBS [4]. Moreover, after the steady-state flow, a slight strain hardening can be noticed. After a certain elongation rate, the possible GBS could lead to a grain growth which will induce a strain hardening and then an increase of the stress. At the maximum location of stress, it can be assumed that if the grain size reached by the $\alpha$ grains is too high, this can lead to an accumulation of stress in the grains and the formation of dislocation contributing to the hardening and then to a softening of the stress [5]. The softening could be due to the activation of continuous dynamic recrystallization (CDRX) because at the final microstructure, the grain size seems to be smaller than at the beginning. Thus, at $750^{\circ} \mathrm{C} 10^{-4} \mathrm{~s}^{-1}$, the mechanical behaviour could be a combination of different mechanisms as a function of the deformation stage. Looking at the evolution of the curve at $920^{\circ} \mathrm{C}$ that undergoes hardening at a high elongation, conventional superplasticity no seems to occur because the steady state flow is no longer observed. Indeed, it could be assumed a lower occurrence of the GBS mechanism, due to the decrease of the number of " $\alpha /$ thin $-\beta / \alpha$ " interfaces by an increase of the distance between each $\alpha$ grains and a modification of the two phases distribution, in favour of another mechanism mainly occurring in the $\beta$ phase. Indeed, at this given temperature, the $\beta$ phase is dominant so the main mechanisms should be expected to be controlled by this phase. The grain growth observed may explain a part of the strain hardening observed on the stress strain curve: larger grains would lead to fewer grain boundaries. Velay et al. have developed a model to predict the stress-strain behaviour at high temperatures [9], taking into account the influence of grain growth on the high hardening. However, the prediction failed at $920^{\circ} \mathrm{C}$. This reveals that another microstructural change and then another mechanism of deformation than grain growth or a collaboration of several mechanisms could be involved. Different mechanisms are possible such as the diffusion at grain boundaries, atomic diffusion in the grains volume or dislocation climb [12]. At this step of investigation, the volume diffusion in the $\beta$ phase could be expected with a dislocation climb, which is favoured at high temperatures. However, no assumption can be made on the evolution and the role of the $\beta$ phase because the number of analysed grains is no sufficient after slow cooling rate and so the counting statistics are not good enough. 


\section{Conclusions}

Ti-6Al-4V titanium alloy was investigated at $750^{\circ} \mathrm{C}$ and $920^{\circ} \mathrm{C}$ for a strain rate of $10^{-4} \mathrm{~s}^{-1}$. At each temperatures, different mechanisms seem to be involved throughout the deformation. First the stress strain curves have demonstrated a combination of hardening, steady-state flow characteristics of a superplastic flow and softening at $750^{\circ} \mathrm{C}$ instead of a high hardening with low stress at the first stage of deformation at $920^{\circ} \mathrm{C}$. At $750^{\circ} \mathrm{C}$, the contribution of dynamic globularization at the beginning of the deformation was supposed due to a decrease of the stress. Regarding the grains orientation, the texture seems to change and become weak with a preferential orientation at $90^{\circ}$ to the sample surface. It can be assumed that the GBS is activated but with an accommodation mechanism, which has not yet been identified. At $920^{\circ} \mathrm{C}$, the high hardening cannot be explained by a grain growth only. As the $\beta$ phase fraction is important at $920^{\circ} \mathrm{C}$, the involved mechanisms may be mainly attributed to the $\beta$ phase. As an example, the high hardening could be due to the grain growth but also to the decrease of the " $\alpha /$ thin- $\beta / \alpha$ " interfaces number. Looking at the evolution of the $\alpha$ grains orientation by EBSD, the texture seems to be weaker with a preferential orientation along the normal to the surface and with a part of grains randomly orientated around this position. So the texture information consolidate the fact that grain boundary sliding is probably not the predominant mechanism but that the predominant mechanism at $920^{\circ} \mathrm{C}$ should be on the $\beta$ phase. The volume diffusion in the $\beta$ phase or the dislocation climb controlled by diffusion could be contemplated.

\section{Acknowledgements}

This study was supported by the Albi Institute Mine Telecom, the Institute Clément Ader laboratory (UMR CNRS 5312), the CIRIMAT laboratory (UMR CNRS 5085) and the materials laboratory at Kagawa University in Japan.

\section{References}

[1] S. Semiatin et al., 'The effect of alpha platelet thickness on plastic flow during hot working of Ti-6Al-4V with a transformed microstructure', Acta Mater. vol.49 (2001) 3565-3573.

[2] S. V. Zherebtsov et al., 'Microstructure evolution and mechanical behavior of ultrafine Ti6Al4V during low-temperature superplastic deformation', Acta Mater., vol. 121 (2016) 152-163.

[3] H. Matsumoto et al., 'Superplasticity of the ultrafine-grained Ti-6Al-4V alloy with a metastable $\alpha$-single phase microstructure, Proceedings of the 13th World Conference on Titanium, John Wiley \& Sons, Inc., Hoboken, USA (2016).

[4] M. Ashby et al., 'Diffusion-accomodated flow and superplasticity', Acta Metall. vol.21 (1973) 149-163.

[5] E. Alabort et al., 'On the mechanisms of superplasticity in Ti-6Al-4V', Acta Mater, vol. 105, (2016) 449-463.

[6] J. S. Kim et al., 'Microstructural analysis on boundary sliding and its accommodation mode during superplastic deformation of Ti-6Al-4V alloy', Materials Science and Engineering: A, vol. 263, no. 2 (1999) 272-280.

[7] S. Malinov et al., 'Resistivity study and computer modelling of the isothermal transformation kinetics of Ti-6Al-4V and Ti-6Al2Sn-4Zr-2Mo-0.08Si alloys', Journal of Alloys and Compounds, vol. 314, no. 1 (2001) 181-192.

[8] S. Semiatin et al., 'Flow behavior and globularization kinetics during hot working of Ti-6Al-4V with a colony alpha microstructure', Materials Science and Engineering: A, vol. 263, no. 2 (1999) 257-271.

[9] V. Velay et al., 'Behavior modeling and microstructural evolutions of Ti-6Al-4V alloy under hot forming conditions', International Journal of Mechanical Sciences, vol.108-109 (2016) 1-13.

[10] A. W. Bowen, 'Texture stability in heat treated Ti-6Al-4V', Materials Science and Engineering, vol. 29 (1977) 19-28.

[11] Z. X. Zhang et al., 'Hot deformation behavior of Ti-6Al-4V alloy: Effect of initial microstructure', Journal of Alloys and Compounds, vol. 718 (2017) 170-181. 
[12] E. Alabort et al., 'Superplasticity in Ti-6Al-4V: characterisation, modelling and applications', Acta Mater. vol.95 (2015) 428442. 